\title{
Redistribution of Rare Metal(loids) during Digenite Exsolution in Porphyry Copper Ores
}

\author{
M. BRODBECK ${ }^{1 *}$, S.H. MCCLENAGHAN ${ }^{1}$, \\ B.S.KAMBER ${ }^{1,2}$, P. REDMOND ${ }^{1,3}$
}

${ }^{1}$ Trinity College Dublin, Department of Geology, iCRAG, College Green, Dublin 2, Ireland

${ }^{2}$ School of Earth and Atmospheric Sciences, Queensland University of Technology, Brisbane, Australia

${ }^{3}$ Kobold Metals, 64 Shattuck Square, Berkeley, USA

Porphyry copper deposits contain extractable concentrations of rare metals and metalloids, e.g. $\mathrm{Ag}, \mathrm{Au}, \mathrm{Pd}, \mathrm{Te}$, $\mathrm{Co}, \mathrm{Ga}, \mathrm{Ge}$ and In, some of which are classified as critical elements, whose shortage is considered a limiting factor for key technologies. Understanding the deportment of these trace constituents in major ore minerals in porphyry copper systems is fundamental for inferring geochemical enrichment processes and improving recoveries. After the primary partitioning of rare elements into precipitating sulphides from ore forming fluids, late exsolution processes can lead to their redistribution at the mineral scale. In hypogene ore of some porphyry deposits, bornite is intergrown with digenite, (e.g. Bingham Canyon or Batu Hijau). This association is commonly interpreted as an exsolution product from a copper-rich precursor bornite solid solution. This seems valid for Bingham Canyon, because sulphide deposition occurred in a temperature interval between $430^{\circ}$ to $350^{\circ} \mathrm{C}$ [1], in which a complete bornite-digenite solid solution exists above $330^{\circ} \mathrm{C}$. Laser Ablation ICP-MS maps of bornite-digenite intergrowths from Bingham Canyon visualise trace-element partitoning between these two mineral species. Silver, $\mathrm{Au}$, and $\mathrm{Te}$ are distinctly enriched in digenite, while $\mathrm{Se}$ is homogenously distributed. Tin, Bi and In appear to be largely retained in bornite, but exhibit more complex zoning. Lower concentrations of these elements occur in a peripheral zone around digenite, where a stress field likely developed due to accumulating lattice distortions during digenite growth. Thus, stress-induced diffusion seems a plausible causative mechansim. Results show that the digenite exsolution processes can result in complex deportment of rare metals and metalloids in copper ores, with potential implications for geometallurgy.

[1] The Bingham Canyon porphyry $\mathrm{Cu}-\mathrm{Mo}-\mathrm{Au}$ deposit. III. Zoned copper-gold ore deposition by magmatic vapor expansion. Landtwing, M.R., Furrer, C., Redmond, P.B., Pettke, T., Guillong, M., Heinrich, C.A. (2010), Economic Geology105(1), 91-118 